
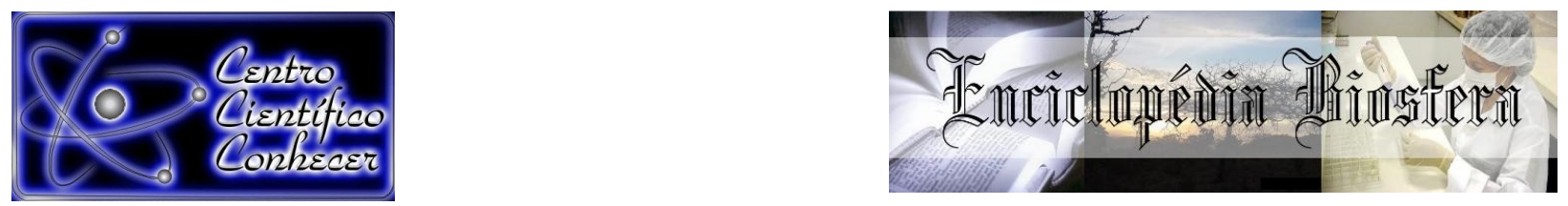

\title{
PRODUÇÃO DE ENZIMAS HIDROLÍTICAS EXTRACELULARES POR ACTINOBACTÉRIAS ORIUNDAS DO SOLO E SERRAPILHEIRA DE REGIÃO SEMIÁRIDA
}

Jessica Barros Arrais Cruz Lopes ${ }^{1}$; Valéria Maria Araújo Silva²; Fernando Gouveia

Cavalcante ${ }^{3}$; Suzana Cláudia Silveira Martins ${ }^{4}$; Claudia Miranda Martins ${ }^{5}$

${ }^{1}$ Graduada em Ciências Biológicas pela Universidade Federal do Ceará- Campus do Pici, Fortaleza - Ceará, Brasil.

${ }^{2}$ Doutoranda do Programa de Pós-graduação em Ecologia e Recursos Naturais da Universidade Federal do Ceará;

${ }^{3}$ Doutorando do Programa de Pós-graduação em Ecologia e Recursos Naturais da Universidade Federal do Ceará;

${ }^{4}$ Professora Doutora do Departamento de Biologia da Universidade Federal do Ceará ${ }^{5}$ Professora Doutora do Departamento de Biologia da Universidade Federal do Ceará

E-mail: (claudia.miranda.martins@gmail.com)

Recebido em: 06/04/2018 - Aprovado em: 10/06/2018 - Publicado em: 20/06/2018 DOI: 10.18677/EnciBio_2018A93

\begin{abstract}
RESUMO
As actinobactérias são micro-organismos que produzem uma notável variedade de metabólitos secundários. Dentre esses produtos, as enzimas se destacam devido à sua ampla aplicabilidade biotecnológica e industrial. Além disso, essas bactérias são responsáveis por importantes interações ecológicas presentes nos solos. Analisouse e comparou-se a produção de enzimas hidrolíticas, amilase e celulase, em 58 cepas de actinobactérias provenientes do solo e serrapilheira coletadas na Estação Ecológica de Aiuaba $(\mathrm{Ce})$, região semiárida do nordeste brasileiro. No teste amilolítico, 98,27\% das cepas, apresentaram halo de degradação, enquanto que no teste celulolítico, $75,86 \%$ das cepas, demonstraram halo de degradação. Os testes estatísticos realizados demonstraram que não houve diferença significativa na atividade enzimática das cepas do solo e serrapilheira. Concluiu-se que houve maior produção da enzima amilase que da enzima celulase e que a origem das actinobactérias não afetou significativamente sua atividade enzimática.
\end{abstract}

PALAVRAS-CHAVE: Caatinga, Amilase, Celulase.

\section{PRODUCTION OF EXTRACELLULAR HYDROLITIC ENZYMES BY ACTINOBACTERIA FROM SOIL AND LITTER OF SEMIARID REGION}

\begin{abstract}
Actinobacteria are microorganisms that produce a remarkable variety of secondary metabolites. Among these products, the enzymes stand out due to their wide biotechnological and industrial applicability. In addition, these bacteria are responsible for important ecological interactions in soils. The production of hydrolytic enzymes, amylase and cellulase was analyzed and compared to 58 strains of actinobacteria from the soil and litter collected at the Aiuaba Ecological Station $(\mathrm{Ce})$,
\end{abstract}


a semi-arid region of northeastern Brazil. The degradation halo in the amylase test was observed in $98.27 \%$ of the strains while in the cellulolytic test was $75.86 \%$. Statistical tests showed that there was no significant difference in the enzymatic activity of soil and litter strains. It was concluded that the production of the amylase was higher than the cellulase and that the origin of actinobacteria did not affect significantly its enzymatic activity.

KEYWORDS: Caatinga, Amylase, Cellulase.

\section{INTRODUÇÃO}

Actinobactérias compreendem um grupo de bactérias Gram-positivas com DNA rico em citosina e guanina e que abrange diversos gêneros, dentre os quais se destacam Salinispora, Frankia, Nocardia, Micromonospora e Streptomyces por sua ampla distribuição, estando presentes em ambientes terrestres, marinhos, regiões de mangue e em condições extremófilas (BALLAV et al., 2015; SHIVLATA; SATYANARAYANA; 2015 BARKA et al., 2016).

A ubiquidade desses micro-organismos pode ser explicada pelo fato de terem alta diversidade metabólica, podendo utilizar diversas fontes de carbono, e possuírem uma grande capacidade de produzir esporos (McCARTHY; WILLIAMS, 1992; SAKURE et al., 2015).

Além de sua reconhecida habilidade na manufaturação de metabólitos secundários de grande importância biotecnológica e industrial, tais como enzimas e antibióticos, as actinobactérias possuem grande importância ecológica devido às interações que realizam com outros micro-organismos e plantas presentes no solo (LAM, 2006; MANIVASAGAN, 2014; SREEVIDYA et al., 2016; BEHIE et al., 2017).

No solo, ambiente heterogêneo e de elevada complexidade química, física e biológica, as actinobactérias apresentam grande abundância e diversidade, e realizam funções primordiais na degradação de substratos ricos em fonte de carbono e de difícil degradação, como amido e celulose (TYC et al., 2016; BATTHI et al., 2017).

A região do semiárido nordestino apresenta um solo composto por uma fina camada de serrapilheira e a predominância de rochas cristalinas, tais rochas dificultam o acúmulo de água subterrânea devido sua baixa porosidade (ZANELLA, 2014). Essas características físicas do solo associadas a elevadas temperaturas e baixas precipitações pluviométricas podem acarretar em redução da carga microbiana nos solos da região, interferindo assim, na dinâmica de ciclagem de compostos orgânicos e na disponibilização de nutrientes (ARAÚJO, 2011; BULL; ASENJO, 2013).

No semiárido, onde a escassez de matéria orgânica e nitrogênio são fatores críticos, a ciclagem dos compostos presentes no solo é fundamental para manutenção dos ciclos biogeoquímicos e para a disponibilidade de nutrientes (LEMOS; MEGURA, 2010). Neste sentido, a existência de actinobactérias capazes de degradar substratos amilolíticos e celulolíticos favorecendo a ciclagem de nutrientes através da degradação de polissacarídeos complexos, é fundamental para manutenção dos componentes vivos deste ambiente. Dessa forma, o objetivo desse estudo foi a avaliação da produção de enzimas hidrolíticas através da determinação do potencial enzimático e comparação do índice enzimático entre estirpes de actinobactérias oriundas do solo e da serrapilheira da Estação Ecológica de Aiuaba (Ce). 


\section{MATERIAL E MÉTODOS}

\section{Origem das cepas}

Um total de 58 cepas de actinobactérias utilizadas neste estudo foram isoladas e caracterizadas do solo e serrapilheira da Unidade de Conservação Estação Ecológica de Aiuaba (Esec de Aiuaba) por Lima et al. (2014). Destas 19 foram provenientes do solo (Ac 8, Ac 9, Ac 21, Ac 23, Ac 24, Ac 31, Ac 32, Ac 36, Ac 46, Ac 49, Ac 50, Ac 54, Ac 55, Ac 56, Ac 57, Ac 58, Ac 59, Ac 60, Ac 61) e 39 oriundas da serrapilheira (Ac 1, Ac 2, Ac 3, Ac 4, Ac 5, Ac 6, Ac 7, Ac 10, Ac 11, Ac 12, Ac 13, Ac 14, Ac 15, Ac 16, Ac 17, Ac 18, Ac 20, Ac 22, Ac 25, Ac 26, Ac 27, Ac 28, Ac 29, Ac 30, Ac 33, Ac 34, Ac 35, Ac 37, Ac 38, Ac 40, Ac 41, Ac 42, Ac 43, Ac 44, Ac 45, Ac 47, Ac 48, Ac 51, Ac 53). Essas cepas fazem parte da Coleção de Culturas de Actinobactérias do Semiárido do Laboratório de Microbiologia Ambiental (LAMAB) da Universidade Federal do Ceará, Departamento de Biologia.

\section{Atividade Enzimática}

A avaliação da atividade enzimática ocorreu com a utilização dos meios de cultivo Ágar-amido (ALARIYA et al., 2013) e Ágar-celulose (COURI; FARIAS, 1995). As actinobactérias foram inoculadas nos respectivos meios de cultivo na forma de spot e em quadruplicata e colocadas em B.O.D. a $28^{\circ} \mathrm{C}$ durante 10 dias. Foram realizados dois ensaios.

Para a avaliação da produção de amilase foi adicionada em cada placa de Petri $10 \mathrm{~mL}$ de solução de lugol deixando-se agir durante um minuto. O lugol cora o meio com uma tonalidade de azul escuro e a presença de um halo claro ao redor da colônia constitui um indicativo da atividade amilolítica. Para revelação da atividade celulolítica foi adicionada $10 \mathrm{~mL}$ de solução vermelho-congo em cada placa e após 15 minutos o sobrenadante foi descartado e adicionados $10 \mathrm{~mL}$ de $\mathrm{NaCl}(2 \mathrm{M})$ o qual depois de 30 minutos o excedente foi retirado e observado a presença de um halo de hidrólise ao redor da colônia. O meio contendo celulose cora de vermelho e a presença de um halo alaranjado ao redor da colônia significa que o teste é positivo para produção de celulase.

\section{Determinação do Índice enzimático}

O índice enzimático (IE) foi obtido a partir da relação entre o diâmetro do halo de hidrólise (Dh) e o diâmetro da colônia (Dc), utilizando-se a seguinte equação:

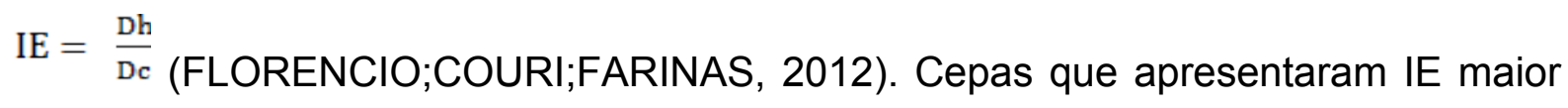

que 2 foram consideradas potencialmente produtoras da enzima (SILVA et al., 2015). As medidas de cada IE foram obtidas em milímetros e analisadas utilizandose o programa estatístico Past (2003). Inicialmente foi verificada a normalidade dos dados através do teste de Shapiro-Wilk, e logo após as médias dos índices enzimáticos foram submetidas a uma ANOVA (análise de variância) para comparar os resultados das cepas oriundas do solo e serrapilheira.

\section{RESULTADOS E DISCUSSÃO}

Atividade Enzimática

Dentre as 58 cepas de actinobactérias analisadas a Ac 29, oriunda da serrapilheira, não hidrolisou o amido. Na atividade amilolítica, nove cepas $(47,36 \%)$ 
nativas do solo apresentaram IE $>2$, enquanto que 14 cepas $(35,89 \%)$ procedentes da serrapilheira mostram o mesmo resultado. Destas, apenas duas cepas destacaram-se com IE superior a três, Ac 36 e Ac 38, provenientes da serrapilheira e do solo, respectivamente (Tabela 1 e 2).

TABELA 1: Índice enzimático amilolítico de estirpes de actinobactérias oriundas da serrapilheira da Estação de Ecológica de Aiuaba.

\begin{tabular}{|c|c|c|c|c|}
\hline & Cepas & $\mathrm{Dc}(\mathrm{mm})$ & $\mathrm{Dh}(\mathrm{mm})$ & $\mathrm{IE}$ \\
\hline \multirow[t]{38}{*}{ Serrapilheira } & ac 1 & 20,21 & 37,37 & $1,86 \pm 0,23$ \\
\hline & ac 2 & 21,05 & 39,41 & $1,88 \pm 0,16$ \\
\hline & ac 3 & 13,84 & 21,34 & $1,56 \pm 0,16$ \\
\hline & ac 4 & 14,98 & 36,77 & $2,53 \pm 0,46$ \\
\hline & ac 5 & 17,57 & 34,73 & $1,99 \pm 0,19$ \\
\hline & ac 6 & 33,75 & 45,04 & $1,34 \pm 0,16$ \\
\hline & ac 7 & 16,01 & 36,71 & $2,37 \pm 0,46$ \\
\hline & ac 10 & 26,76 & 40,99 & $1,53 \pm 0,14$ \\
\hline & ac 11 & 35,09 & 44,79 & $1,3 \pm 0,23$ \\
\hline & ac 12 & 10,59 & 30,38 & $2,88 \pm 0,21$ \\
\hline & ac 13 & 21,62 & 42,84 & $2 \pm 0,25$ \\
\hline & ac 14 & 12,8 & 18,58 & $1,4 \pm 0,21$ \\
\hline & ac 15 & 17,79 & 31,03 & $1,76 \pm 0,2$ \\
\hline & ac 16 & 17,48 & 31,26 & $1,83 \pm 0,22$ \\
\hline & ac 17 & 20,99 & 41,45 & $2 \pm 0,3$ \\
\hline & ac 18 & 29,18 & 45,26 & $1,65 \pm 0,25$ \\
\hline & ac 20 & 13,8 & 38,04 & $2,83 \pm 0,48$ \\
\hline & ac 22 & 9,86 & 20,41 & $2,1 \pm 0,25$ \\
\hline & ac 25 & 13,78 & 36,51 & $2,66 \pm 1,01$ \\
\hline & ac 26 & 17,35 & 36,4 & $2,15 \pm 0,377$ \\
\hline & ac 27 & 13,76 & 37,43 & $2,75 \pm 0,34$ \\
\hline & ac 28 & 19,92 & 37,44 & $2,17 \pm 0,78$ \\
\hline & ac 29 & - & - & - \\
\hline & ac 30 & 20,34 & 33,73 & $1,66 \pm 0,17$ \\
\hline & ac 33 & 20,72 & 32,48 & $1,57 \pm 0,14$ \\
\hline & ac 34 & 23,92 & 33,06 & $1,4 \pm 0,2$ \\
\hline & ac 35 & 13,28 & 26,86 & $2,04 \pm 0,2$ \\
\hline & ac 37 & 17,07 & 33,01 & $1,98 \pm 0,27$ \\
\hline & ac 38 & 13,72 & 39,47 & $3,14 \pm 1,11$ \\
\hline & ac 40 & 11,15 & 16,97 & $1,51 \pm 0,15$ \\
\hline & ac 41 & 22,79 & 34,94 & $1,52 \pm 0,09$ \\
\hline & ac 42 & 15,43 & 22,35 & $1,45 \pm 0,13$ \\
\hline & ac 43 & 28,88 & 43,68 & $1,52 \pm 0,26$ \\
\hline & ac 44 & 30 & 42,94 & $1,43 \pm 0,13$ \\
\hline & ac 45 & 16,4 & 39,49 & $2,48 \pm 0,42$ \\
\hline & ac 47 & 30,12 & 44,06 & $1,47 \pm 0,15$ \\
\hline & ac 48 & 12,78 & 22,01 & $17.57 \pm 0,16$ \\
\hline & ac 51 & 19,01 & 35,27 & $1,89 \pm 0,27$ \\
\hline
\end{tabular}




\begin{tabular}{rrrr}
\hline ac 53 & 16,13 & 30,92 & $1,94 \pm 0,3$ \\
\hline$(-)$ ausência de atividade amilolítica &
\end{tabular}

A abundância do amido no solo pode estar relacionado com o fato de que é o principal composto de reserva das plantas e uma importante fonte de energia para vários outros organismos (AMARAL et al., 2007).

As amilases microbianas são uma fonte importante de enzimas que apresentam abundância e grande plasticidade, sobretudo as de origem bacteriana, apresentando grande aplicabilidade biotecnológica (ALARIYA et al., 2013). Diversas pesquisas apontam para o potencial de actinobactérias do solo na síntese de enzimas amilolíticas, secretadas como resultado de sua digestão extracelular (SILVA et al., 2015; ALVES et al., 2016; JANAKI, 2017).

TABELA 2: Índice enzimático amilolítico de estirpes de actinobactérias oriundas do solo da Estação de ecológica de Aiuaba.

\begin{tabular}{ccccc}
\hline & Cepas & Dc $(\mathrm{mm})$ & Dh $(\mathrm{mm})$ & $\mathrm{IE}$ \\
\hline Solo & ac 8 & 22,09 & 37,44 & $1,69 \pm 0,1$ \\
& ac 9 & 22,49 & 42,75 & $1,9 \pm 0,08$ \\
ac 21 & 16,15 & 31,02 & $2,04 \pm 0,6$ \\
ac 23 & 19,92 & 40,26 & $2,1 \pm 0,49$ \\
ac 24 & 29,45 & 39,06 & $1,33 \pm 0,17$ \\
ac 31 & 11,54 & 21,15 & $2,61 \pm 1,26$ \\
ac 32 & 14,03 & 38,03 & $2,77 \pm 0,49$ \\
ac 36 & 13,49 & 39,98 & $3,08 \pm 0,64$ \\
ac 46 & 16,06 & 29,2 & $2,01 \pm 0,68$ \\
ac 49 & 20,44 & 43,25 & $2,14 \pm 0,29$ \\
ac 50 & 14,97 & 26,36 & $1,76 \pm 0,21$ \\
ac 54 & 18,47 & 31,21 & $1,73 \pm 0,26$ \\
Ac 55 & 28,57 & 47,57 & $1,67 \pm 0,19$ \\
ac 56 & 25,22 & 37,37 & $1,5 \pm 0,17$ \\
ac 57 & 19,52 & 40,9 & $2,18 \pm 0,57$ \\
ac 58 & 17,84 & 42,94 & $2,44 \pm 0,45$ \\
ac 59 & 26,68 & 38,02 & $1,45 \pm 0,16$ \\
ac 60 & 22,21 & 36,34 & $1,63 \pm 0,06$ \\
ac 61 & 23,79 & 41,92 & $1,8 \pm 0,37$ \\
\hline
\end{tabular}

(-) ausência de atividade amilolítica

Neste sentido, a presença de micro-organismos em solos semiáridos com capacidade de síntese de enzimas extracelulares com potencial para degradação de susbtratos que contenham o amido, sinaliza para uma possível disponibilização de carbono livre, que pode ser utilizado por outros organismos neste habitat.

Segundo Silva et al. (2015) as actinobactérias podem ser classificadas em relação a produção de enzima como cepas fortemente produtoras (IE $\geq 2$ ), moderadamente produtoras $(1,5 \leq \mathrm{IE}<2)$, fracamente produtoras $(1<\mathrm{IE}<1,5)$ e não produtoras (ausência de halo de hidrólise). Assim, seguindo esta classificação, das 58 cepas de actinobactérias avaliadas, 23 foram classificadas como fortemente produtoras (39,65\%), sendo 14 oriundas da serrapilheira (Ac 4, Ac 7, Ac 12, Ac 13, Ac 17, Ac 20, Ac 21, Ac 22, Ac 25, Ac 26, Ac 27, Ac 28, Ac 35, Ac 38, Ac 45) e nove nativas do solo (Ac 23, Ac 31, Ac 32, Ac 36, Ac 46, Ac 49, Ac 57, Ac 58), enquanto 
$24(43,10 \%)$ actinobactérias foram classificadas como moderadamente produtoras, dentre as quais 18 provenientes da serrapilheira (Ac 1, Ac 2, Ac 3, Ac 10, Ac 15, Ac 16, Ac 18, Ac 30, Ac 33, Ac 37, Ac 40, Ac 43, Ac 47, Ac 48, Ac 53) e sete do solo (Ac 8, Ac 9, Ac 50, Ac 54, Ac 55, Ac 56, Ac 60, Ac 61). Das actinobactérias classificadas como fracamente produtoras, sete foram procedentes da serrapilheira (Ac 6, Ac 11, Ac 14, Ac 34, Ac 41, Ac 42) e apenas duas do solo (Ac 24 e Ac 59). Somente a cepa Ac 29 foi identificada como não produtora (Figura 1).

Estudos realizados por Alves et al. (2016) com actinobactérias isoladas de solo rizosférico da região do Baixo Acaraú, município de Marco $(\mathrm{Ce})$, indicaram que $80 \%$ (31) das cepas testadas apresentaram IE $>2$, demonstrando forte atividade amilolítica. Estes resultados diferem dos relatados no presente estudo que apontam que o maior percentual das cepas analisadas $(43,10 \%)$ apresentou moderada atividade $(1,5 \leq \mathrm{IE}<2)$. Entretanto, vale ressaltar que a atividade amilolítica foi maior nas cepas nativas da serrapilheira do que oriundas do solo, o que confirma o fato de que a biomassa microbiana e a atividade enzimática tende a diminuir com a profundidade do solo, uma vez que há redução da matéria orgânica (OSAKl; NETTO, 2012; STONE; DEFOREST; PLANTE, 2014).

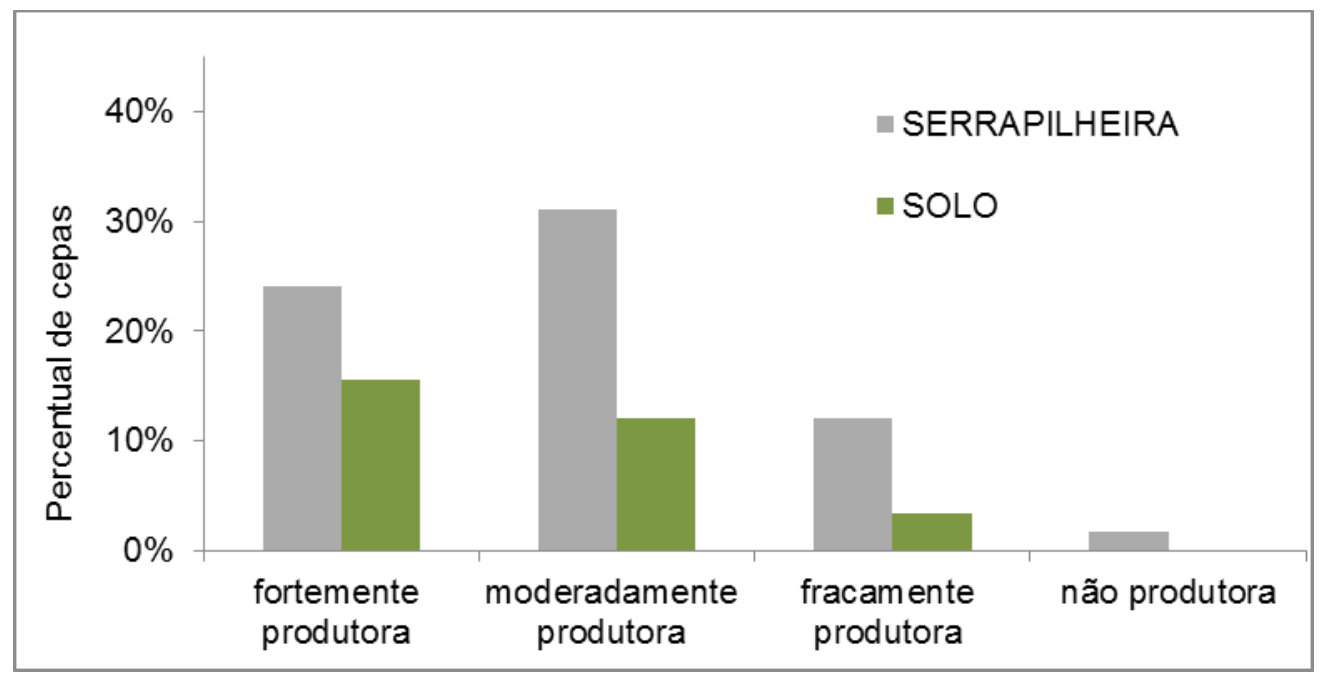

FIGURA 1: Classificação das estirpes de actinobactérias quanto à produção de amilase.

Quanto a atividade celulolítica, das 58 actinobactérias testadas, 44 cepas $(75,86 \%)$ apresentaram halo de degradação da carboximetilcelulose. Destas, 11 cepas $(57,9 \%)$ nativas do solo apresentaram IE $>2$, enquanto que 23 cepas $(58,7 \%)$ da serrapilheira evidenciaram o mesmo resultado. As cepas que se destacaram com IE $>3$ foram Ac 1, Ac 2, Ac 4, Ac 11, Ac 13, Ac 20 e Ac 26 originárias da serrapilheira (Tabela 3) e Ac 9 e Ac 32 do solo (Tabela 4). Estes resultados assemelham-se com os verificados para atividade amilolítica das referidas cepas, uma vez que o maior percentual de cepas com atividade celulolítica foi verificado naquelas provenientes da serrapilheira. 
TABELA 3: Índice enzimático celulolítico de cepas de actinobactérias oriundas da serrapilheira da Estação de ecológica de Aiuaba.

\begin{tabular}{|c|c|c|c|c|}
\hline & Cepas & $\mathrm{Dc}(\mathrm{mm})$ & $\mathrm{Dh}(\mathrm{mm})$ & IE \\
\hline \multirow[t]{38}{*}{ Serrapilheira } & ac 1 & 10,07 & 38,53 & $3,93 \pm 0,85$ \\
\hline & ac 2 & 9,99 & 37,02 & $3,82 \pm 0,71$ \\
\hline & ac 3 & - & - & - \\
\hline & ac 4 & 10,5 & 37,44 & $3,61 \pm 0,56$ \\
\hline & ac 5 & - & - & - \\
\hline & ac 6 & 23,97 & 40,13 & $1,6 \pm 0,19$ \\
\hline & ac 7 & 14,19 & 40,31 & $2,86 \pm 0,28$ \\
\hline & ac 10 & 15,92 & 37,46 & $2,97 \pm 1,4$ \\
\hline & ac 11 & 6,69 & 28,02 & $4,33 \pm 0,71$ \\
\hline & ac 12 & - & - & - \\
\hline & ac 13 & 9,28 & 38,61 & $4,27 \pm 0,83$ \\
\hline & ac 14 & - & - & - \\
\hline & ac 15 & 22,32 & 40,68 & $1,93 \pm 0,43$ \\
\hline & ac 16 & - & - & - \\
\hline & ac 17 & 15,42 & 31,17 & $2,03 \pm 0,23$ \\
\hline & ac 18 & 6,84 & 19,87 & $2,98 \pm 0,86$ \\
\hline & Ac 20 & 6,77 & 30,48 & $4,57 \pm 1,76$ \\
\hline & ac 22 & 7,92 & 13,44 & $1,77 \pm 0,28$ \\
\hline & ac 25 & 12,74 & 15,11 & $2,73 \pm 0,179$ \\
\hline & ac 26 & 8,37 & 25,23 & $3,02 \pm 0,56$ \\
\hline & ac 27 & 21,34 & 41,36 & $2,09 \pm 0,46$ \\
\hline & ac 28 & 12,17 & 27,42 & $2,26 \pm 0,29$ \\
\hline & ac 29 & - & - & - \\
\hline & ac 30 & 15,36 & 32,31 & $2,15 \pm 0,44$ \\
\hline & ac 33 & 12,37 & 28,9 & $2,34 \pm 0,28$ \\
\hline & ac 34 & 10,05 & 16,71 & $1,69 \pm 0,44$ \\
\hline & ac 35 & - & - & - \\
\hline & ac 37 & 13,06 & 35,92 & $2,75 \pm 0,22$ \\
\hline & ac 38 & 10,98 & 32,12 & $2,99 \pm 0,49$ \\
\hline & ac 40 & - & - & - \\
\hline & ac 41 & 12,66 & 30,35 & $2,45 \pm 0,59$ \\
\hline & ac 42 & 11,75 & 21,98 & $1,88 \pm 0,23$ \\
\hline & ac 43 & 13,88 & 30,45 & $2,24 \pm 0,69$ \\
\hline & ac 44 & - & - & - \\
\hline & ac 45 & - & - & - \\
\hline & ac 47 & 12,28 & 26,77 & $2,23 \pm 0,44$ \\
\hline & ac 48 & 9,52 & 24,78 & $2,6 \pm 0,27$ \\
\hline & ac 53 & 11,48 & 29,89 & $2,67 \pm 0,61$ \\
\hline
\end{tabular}

(-) ausência de atividade celulolítica 
Dentre as cepas de actinobactérias testadas quanto a produção de celulase, $34(58,62 \%)$ foram consideradas fortemente produtoras (IE $\geq 2$ ), sendo que destas, 23 foram oriundas da serrapilheira ( Ac 1, Ac 2, Ac 4, Ac 7, Ac 10, Ac 11, Ac 13, Ac 17, Ac 18, Ac 20, Ac 23, Ac 25, Ac 26, Ac 27, Ac 28, Ac 30, Ac 33, Ac 37, Ac 38, Ac 41, Ac 43, Ac 47, Ac 48, Ac 50, Ac 53) e 11 do solo (Ac 8, Ac 9, Ac 32, Ac 46, Ac 49, Ac 55, Ac 56, Ac 59, Ac 60). Das $10(17,24 \%)$ actinobactérias classificadas como moderadamente produtoras $(1,5 \leq \mathrm{IE}<2)$, cinco foram da serrapilheira (Ac 6 , Ac 15, Ac 22, Ac 34, Ac 42) e cinco do solo (Ac 21, Ac 36, Ac 57, Ac 58, Ac 61).

TABELA 4: Índice enzimático celulolítico de cepas de actinobactérias oriundas do solo da Estação de ecológica de Aiuaba.

\begin{tabular}{llccc}
\hline Cepas & Dc $(\mathrm{mm})$ & Dh $(\mathrm{mm})$ & IE \\
\hline Solo & ac 8 & 10,97 & 34,44 & $2,82 \pm 0,17$ \\
ac 9 & 9,66 & 37,73 & $3,93 \pm 0,45$ \\
ac 21 & 10,53 & 21,31 & $1,94 \pm 0,4$ \\
ac 23 & 12,33 & 27,06 & $2,9 \pm 1,46$ \\
ac 24 & - & - & - \\
ac 31 & - & - & - \\
ac 32 & 4,97 & 20,12 & $4,28 \pm 1,03$ \\
ac 36 & 10,11 & 18,24 & $1,81 \pm 0,17$ \\
ac 46 & 10,77 & 30,26 & $2,81 \pm 0,29$ \\
ac 49 & 10,49 & 20,85 & $2,15 \pm 0,31$ \\
ac 50 & 13,82 & 34,2 & $2,55 \pm 0,62$ \\
ac 51 & - & - & - \\
ac 54 & - & - & - \\
ac 55 & 7,72 & 18,62 & $2,5 \pm 0,77$ \\
ac 56 & 15,85 & 36,72 & $2,35 \pm 0,36$ \\
ac 57 & 13,38 & 25,73 & $1,87 \pm 0,28$ \\
ac 58 & 17,78 & 27,26 & $1,53 \pm 0,08$ \\
ac 59 & 12,77 & 37,01 & $2,09 \pm 0,37$ \\
ac 60 & 14,18 & 40,19 & $2,29 \pm 0,46$ \\
ac 61 & 16,6 & 32,24 & $1,94 \pm 0,17$ \\
\hline
\end{tabular}

(-) ausência de atividade celulolítica

Nenhuma cepa foi classificada como fracamente produtora $(1<\mathrm{IE}<1,5)$ enquanto que 14 cepas $(24,13 \%)$ foram identificadas como não produtoras, sendo 11 nativas da serrapilheira (Ac 3, Ac 5, Ac 12, Ac 14, Ac 16, Ac 29, Ac 35, Ac 40, Ac 44, Ac 45, Ac 51) e três do solo (Ac 24, Ac 31, Ac 54) (Figura 2).

A celulose é um polissacarídeo linear de estrutura complexa que apresenta grande abundância, sendo degradado preferencialmente por fungos e bactérias (GUPTA et al., 2011). As actinobactérias são apontadas como produtoras de enzimas celulolíticas. Estudos atestam o potencial celulolítico deste grupo microbiano isolado de diversos ambientes (MEENA et al., 2013; HENG; HAMZAH, 2014; JARALLA et al., 2014; SILVA et al., 2015; ALVES et al., 2016).

Alves et al. (2016) ao avaliarem a atividade celulolítica de cepas de actinobactérias isoladas do bioma caatinga observaram que cerca de $77 \%$ das 
cepas foram produtoras de enzimas celulolíticas, resultado similar ao constatado no presente estudo. Já Minotto et al. (2014) ao verificarem a mesma atividade por cepas de actinobactérias endofíticas de raízes de tomate, constataram que apenas $30 \%$ (8) das cepas apresentaram atividade.

Assim como observado para atividade amilolítica, percentual significativo das estirpes da serrapilheira apresentaram atividade celulolítica forte ou moderada. De acordo com López-Mondéjar et al. (2016) bactérias com habilidade na degradação de compostos a base de celulose são comuns na camada superficial do solo. Neste sentido, a presença de micro-organismos comprovadamente solubilizadores de compostos ricos em celulose, provenientes principalmente do substrato arbóreo, constitui um elemento importante na reciclagem de material biológico em solos semiáridos, auxiliando assim, na incorporação de nutrientes ao solo e na disponibilização de fontes de carbono relevantes para outros organismos.

Um estudo realizado em comunidades bacterianas do solo da República Tcheca indicou que houve maior diversidade e uniformidade na serrapilheira do que no solo (URBANOVÁ; ŠNAJDR; BALDRIAN, 2015). Resultado similar foi apontado por Žifčáková et al. (2016) ao avaliarem solo de floresta de coníferas onde a serrapilheira continha maior biomassa de bactérias e fungos do que no solo. Além disso, estes mesmos autores também encontraram uma maior quantidade de enzima celulase na serrapilheira do que no solo.

Contudo, a análise de variância (ANOVA) demonstrou que não houveram diferenças significativas $(p>0,05)$ entre as cepas oriundas do solo e da serrapilheira em relação a produção de enzimas amilolíticas e celulolíticas. Apesar dos resultados encontrados no presente trabalho não apontem para diferenças estatísticas em relação a produção de enzimas extracelulares entre cepas das diferentes camadas do solo, pode-se ressaltar que há maior carga de matéria orgânica na camada superficial do solo, o que gera maior quantidade de recursos nutricionais para os organismos vivos que habitam esta região do solo, influenciando positivamente sua microbiota.

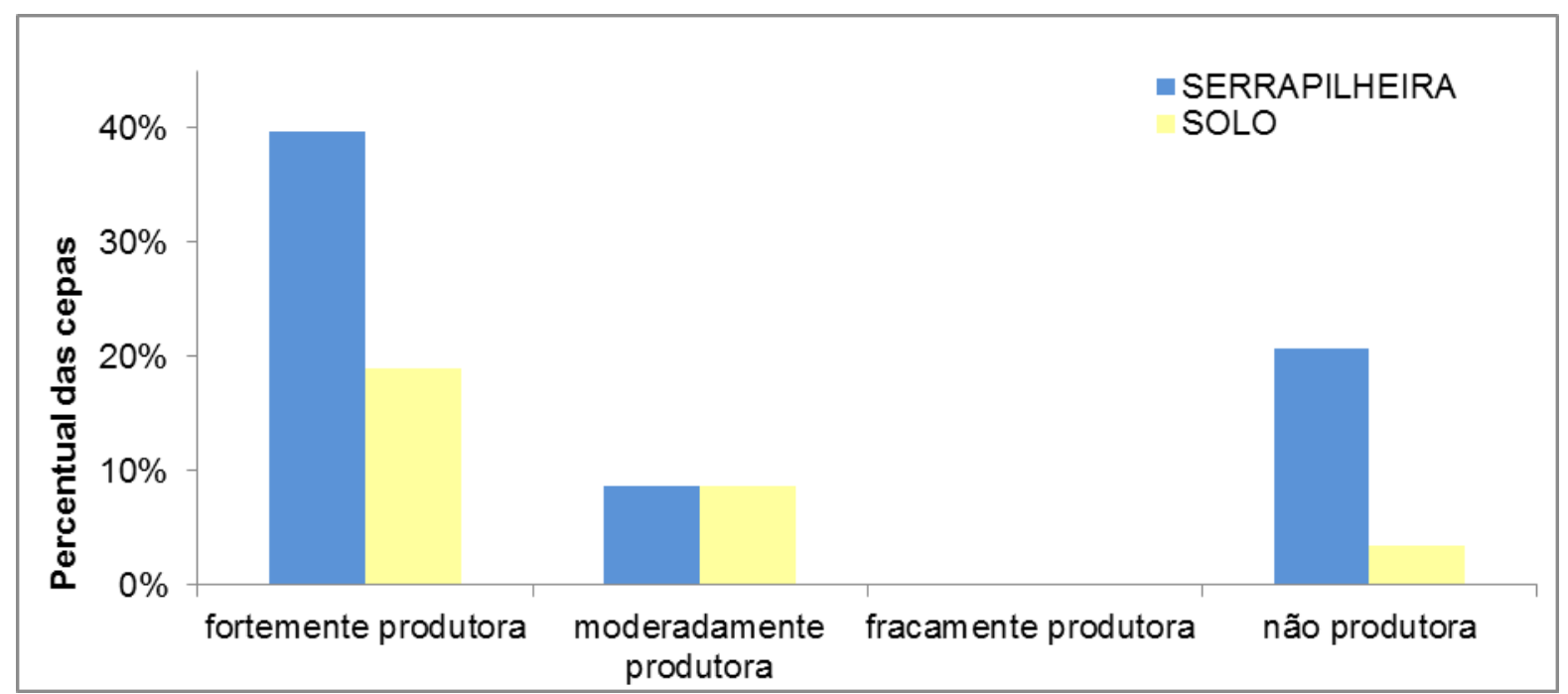

FIGURA 2: Classificação das cepas de actinobactérias quanto à produção de celulase.

De acordo com Burns et al. (2013) os agentes que atuam de forma direta na decomposição da matéria orgânica são enzimas extracelulares presentes no solo, originárias da atividade metabólica de diferentes micro-organismos e que agem na 
quebra de compostos complexos contendo carbono e nitrogênio, participando assim, de importantes processos de ciclagem e incorporação de nutrientes para ambiente.

Como mencionado anteriormente, parte significativa das cepas avaliadas neste estudo apresentaram produção de enzimas amilolítica e celulolítica, contudo foi possível identificar que $44(75,86 \%)$ cepas de actinobactérias, apresentaram produção de ambas as enzimas, sendo $27,59 \%$ oriundas do solo e $48,27 \%$ da serrapilheira. Apenas $13(22,42 \%)$ cepas demonstraram produção apenas de amilase, enquanto que a cepa Ac 29, oriunda da serrapilheira, não apresentou halo de degradação para nenhuma das enzimas avaliadas (Figura 3).

A prevalência de cepas produtoras de ambas as enzimas na serrapilheira em relação ao solo (Figura 3) pode ser atribuída à predominância de biopolímeros de estrutura complexa e altamente diversificada, necessitando assim de uma atividade conjunta de vários micro-organismos para completa degradação desses compostos (BOER, 2005; ŠTURSOVÁ et al., 2012; BURNS et al., 2013; URBANOVÁ; ŠNAJDR; BALDRIAN, 2015). Para Šnajdr et al. (2013) a composição da comunidade microbiana representa um melhor prognóstico para a atividade enzimática na serrapilheira do que no solo.

A presença de um elevado percentual de cepas produtoras de enzimas é um atributo importante para a renovação de nutrientes no solo do semiárido, pois é apenas dessa forma que os polissacarídeos orgânicos complexos são degradados e, posteriormente, absorvidos (CADWELL, 2005).

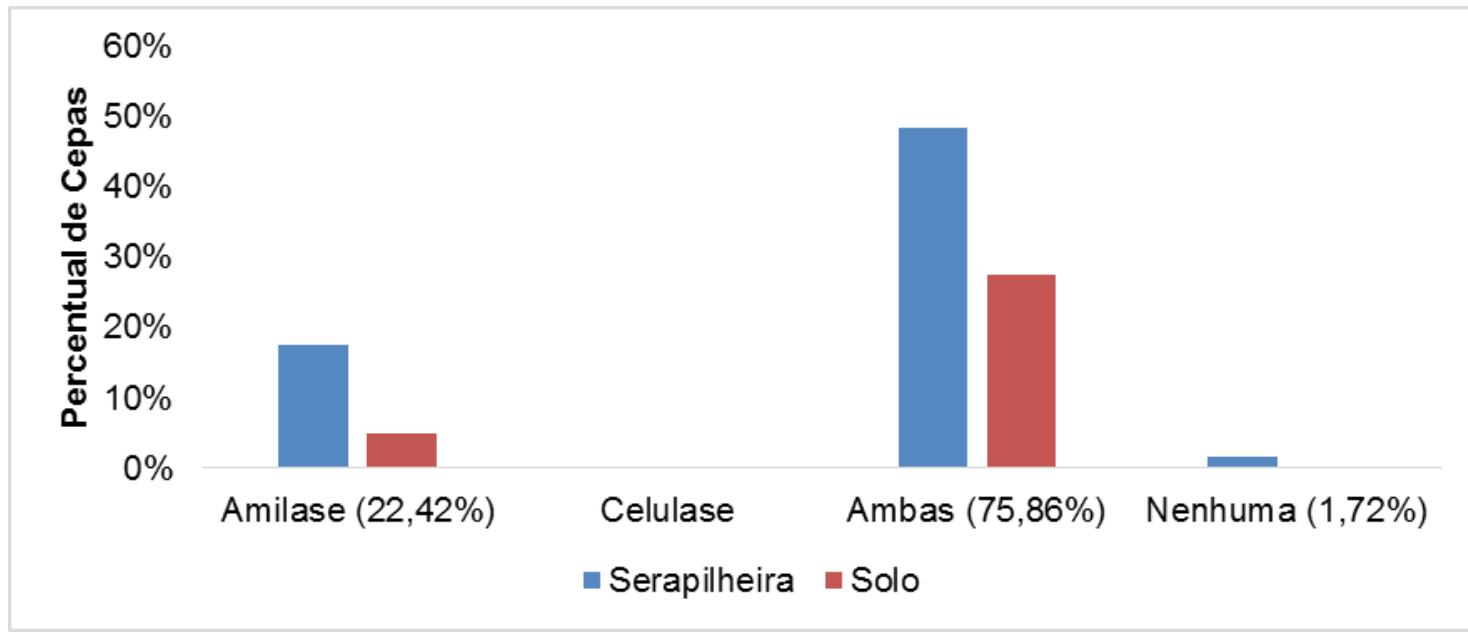

FIGURA 3: Porcentagem de actinobactérias produtoras de celulase e amilase no solo e na serrapilheira.

O teste de normalidade realizado, Shapiro-Wilk, demonstrou que os dados acompanharam a linha de tendência e o $p$ (índice de significância) foi maior que 0 $(p>0)$, assim, a distribuição dos dados é normal. Além disso, essas amostras seguem o teorema de limite central que afirma que quanto maior é a amostra, maior é a chance de suas variáveis serem distribuídas normalmente (ABBAD; TORRES, 2002).

Sabe-se que a biomassa microbiana e a atividade enzimática são reconhecidas como bons indicadores da qualidade do solo (LÓPEZ-AIZPÚN et al., 2018). Dessa forma, a presença de micro-organismos, como as actinobactérias, com capacidade de síntese de enzimas extracelulares capazes de quebrar moléculas de natureza complexa em diversas camadas do solo de regiões semiáridas, pode ser 
um bom indicador da capacidade deste ambiente de suportar uma intricada rede de vida que resiste as condições adversas apresentadas por este ambiente.

\section{CONCLUSÃO}

As cepas de actinobactérias oriundas da Estação Ecológica de Aiuaba tem potencial para a produção de enzimas extracelulares. Houve maior produção da enzima amilase, 98,27\% comparada a celulase, 75,86\%. Apesar da maior presença de actinobactérias produtoras de enzimas no solo que na serrapilheira (amilase, $100 \%$ no solo e $97 \%$ na serrapilheira; celulase $84,21 \%$ no solo e $74,21 \%$ na serrapilheira) a origem das actinobactérias não afetou significativamente sua atividade enzimática.

\section{REFERÊNCIAS}

ABBAD, G. D. S.; TORRES, C. V. Regressão múltipla stepwise e hierárquica em Psicologia Organizacional: aplicações, problemas e soluções. 2002. Disponível em:< http://www.scielo.br/scielo.php?script=sci_arttext\&pid=S1413294X2002000300004/>.DOI: 10.1590/S1413-294X2002000300004 .

ALARIYA, S. S.; SETHI, S.; GUPTA, S.; LAL, G. B. Amylase activity of a starch degrading bacteria isolated from soil. Archives of Applied Science Research, v. 5, n.1, p.15-24, 2013. Disponível em:< https://pdfs.semanticscholar.org/51ef/0b3026947a22ede0e872422909af538e7627.pd f> .Acesso em Fevereiro de 2018.

ALVES, D. A. S.; SILVA, V. M. A.; GARCIA, F. A. C.; MARTINS, S. C. S.; MARTINS, C. M. Produção de celulase e amilase por actinobactérias do semiárido brasileiro. Revista Enciclopédia Biosfera, v. 13, n. 24, p.1303-1315, 2016. Disponível em:< http://www.conhecer.org.br/enciclop/2016b/biologicas/Producao\%20de \%20celulase.pdf>. DOI: 10.18677/EnciBio_2016B_121.

ARAÚJO, S. M. S. A Região Semiárida do Nordeste do Brasil: questões ambientais e possibilidades de uso sustentável dos recursos. Rios Eletrônica-Revista Científica da FASETE. v. 5, 2011. Acesso em Fevereiro de 2018.

AMARAL, L. I. V.; GASPAR, M.; COSTA, P. M. F.; AIDAR, M. P. M.; BUCKERIDGE, M. S. Novo método enzimático rápido e sensível de extração e dosagem de amido em materiais vegetais. Hoehnea, v. 34, n. 4, p. 425-431, 2007. Disponível em:< http://www.scielo.br/scielo.php?pid=S223689062007000400001\&script=sci_arttext>.DOI:10.1590/S223689062007000400001.

BALLAV, S.; KERKAR, S.; THOMAS, S.; AUGUSTINE, N. Halophilic and halotolerant actinomycetes from a marine saltern of $\mathrm{Goa}$, India producing anti-bacterial metabolites. Journal of Bioscience and Bioengineering, v. 119, n.3, p. 323-330, 2015. em:

https://www.sciencedirect.com/science/article/pii/S1389172314003491?via \%3Dihub>DOI: 10.1016/j.jbiosc.2014.08.017. 
BARKA, E. A.; VATSA, P.; SANCHEZ, L.; GAVEAU-VAILLANT, N.; JACQUARD, C.; MEIR-KOLTHOFF, J. P.; KLENK, H.P.; CLÉMENT, C.; OUHDOUCH, Y.; VAN WEZEL, G.P. Taxonomy, physiology, and natural products of Actinobacteria. Microbiology and Molecular Biology Reviews, v. 80, n. 1, p.1-43, 2016. Disponível em: < http://mmbr.asm.org/content/80/1/1.short>.DOI: 10.1128/MMBR.00019-15.

BHATTI, A. A.; HAQ, S.; BHAT, R. A. Actinomycetes benefaction role in soil and plant health. Microbial Pathogenesis, v.111, p.458-467, 2017. Disponível em:<https://www.sciencedirect.com/science/article/pii/S0882401017305880?via \%3Dihub>.doi:10.1016/j.micpath.2017.09.036.

BEHIE, S. W.; BONET, B.; ZACHARIA, V. M.; MCCLUNG, D. J.; TRAXLER, M. F. Molecules to ecosystems: actinomycete natural products in situ. Frontiers in $\begin{array}{lllll}\text { Microbiology, } & \text { v.7, } & \text { p.2149, } 2017 . & \text { Disponível } & \text { em:< }\end{array}$ https://www.frontiersin.org/articles/10.3389/fmicb.2016.02149/full>.DOI:

10.3389/fmicb.2016.02149.

BOER, W. D.; FOLMAN, L. B.; SUMMERBELL, R. C.; BODDY, L. Living in a fungal world: impact of fungi on soil bacterial niche development. FEMS Microbiology Reviews, v.29, n.4, p.795-811, 2005. Disponivel em:< http://onlinelibrary.wiley.com/DOI/10.1016/j.femsre.2004.11.005/full>.DOI: 10.1016/j.femsre.2004.11.005

BULL, A. T.; ASENJO, J. A. Microbiology of hyper-arid environments: recent insights from the Atacama Desert, Chile. Antonie Van Leeuwenhoek, v. 103, n. 6, p. 11731179, 2013. Disponível em: < https://link.springer.com/article/10.1007/s10482-0139911-7>. DOI: 10.1007/s10482-013-9911-7.

BURNS, R. G.; DEFOREST, J.L.; MARXSEN, J.; SINSABAUG, R.L.; STROMBERGER, M.E.; WALLENSTEIN, M.D.; WEINTRAUB, M.N.; ZOPPINI, A. Soil enzymes in a changing environment: current knowledge and future directions. Soil Biology and Biochemistry, v. 58, p. 216-234, 2013. Disponível em:< https://www.sciencedirect.com/science/article/pii/S0038071712004476>.DOI: 10.1016 lj.soilbio.2012.11.009.

CALDWELL, B. A. Enzyme activities as a component of soil biodiversity: a review. Pedobiologia, v. 49, n. 6, p. 637-644, 2005. Disponível em:< https://www.sciencedirect.com/science/article/pii/S0031405605000569?via \%3Dihub>.DOI:10.1016/j.pedobi.2005.06.003.

COURI, S.; FARIAS, A. X. Genetic manipulation of Aspergillus niger for increased synthesis of pectinolytic enzymes. Revista de Microbiologia, v.26, n.4, p.314-317, 1995.

FLORENCIO, C.; COURI, S.; FARINAS, C. S. Correlation between agar plate screening and solid-state fermentation for the prediction of cellulase production by Trichoderma strains. Enzyme Research, p.1-7, 2012. Disponível em:< https://www.hindawi.com/journals/er/2012/793708/abs/>.DOI: 10.1155/2012/793708. 
GUPTA, P.; SAMANT, K.; SAHU, A. Isolation of cellulose-degrading bacteria and determination of their cellulolytic potential. International Journal of Microbiology, v.6, $\quad$ p.1-5, $2011 \quad$ Disponível:< https://www.hindawi.com/journals/ijmicro/2012/578925/abs/>.DOI:

$10.1155 / 2012 / 578925$

HENG, J. L. S.; HAMZAH, H. Biological active compounds from actinomycetes isolated from soil of Langkawi Island, Malaysia. African Journal of Biotechnology, v.13, n.49, p.4523-4528, $2014 . \quad$ Disponível em:< https://www.researchgate.net/profile/Jeffrey_Lim_Seng_Heng/publication/276112361

Biological_active_compounds_from_actinomycetes_isolated_from_soil_of_Langka wi_Island_Malaysia/links/5739779a08ae9ace840d1944.pdf>.DOI: 10.5897/AJJB09.749.

JANAKI, T. Enzymes from Actinomycetes-Review. International Journal of ChemTech Research. v.10, n.2, p.176-182, 2017. Disponível em:http://www.sphinxsai.com/2017/ch_vol10_no2/1/(176-182)V10N2CT.pdf.Acesso em Fevereiro de 2018.

JARALLA, E. M.; AL-DABBAGH, N. N.; HAMEED, N. M.; ABDUL-HUSSAIN, N. Screening for enzymatic production ability and antimicrobial activity of actinomycetes isolated from soil in Hillah/Iraq. Journal of Pharmacy and Biological Sciences, v.9, p.42-47, 2014.Disponível em:< https://pdfs.semanticscholar.org/9b74/f6f595b267f8b1d101324f46f3eb4e98e528.pdf> DOI:10.9790/3008-09564247.

LAM, K. S. Discovery of novel metabolites from marine actinomycetes. Current Opinion in Microbiology, v.9, n.3, p.245-251, 2006. Disponivel em< https://www.sciencedirect.com/science/article/pii/S1369527406000543>.DOI: https://DOI.org/10.1016/j.mib.2006.03.004.

LEMOS, J. R.; MEGURA, M. Florística e fitogeografia da vegetação decidual da Estação Ecológica de Aiuaba, Ceará, Nordeste do Brasil. Revista Brasileira Biociências, $\quad$ v.8, $\quad$ p.34-43, 2010. Disponível $\quad$ em:< http://www.ufrgs.br/seerbio/ojs/index.php/rbb/article/view/1199>.

LIMA, J. V. L.; PINHEIRO, M. S.; GUEDES, L. M. C. Populações microbianas cultiváveis do solo e serrapilheira de uma unidade de conservação no semiárido brasileiro. Enciclopédia Biosfera, v. 10, n. 18, p.2300-2316, 2014. Disponível em:< http://www.conhecer.org.br/enciclop/2014a/AGRARIAS/populacoes.pdf >.

LÓPEZ-MONDÉJAR, R.; ZÜHLKE, D.; BECHER, D.; RIEDEL, K.; BALDRIAN, P. Cellulose and hemicellulose decomposition by forest soil bacteria proceeds by the action of structurally variable enzymatic systems. Scientific Reports, v. 6, p. 1-12, 2016. Disponivel em: < https://www.nature.com/articles/srep25279>.DOI: 10.1038/srep25279.

LÓPEZ-AIZPÚN, M.; ARANGOO-MORAA, C.; SANTAMARÍAA, C.; LASHERASA, E.; SANTAMARÍAA, J. M.; CIGANDAB, V. S.; CÁRDENASC, L. M.; ELUSTONDOA, D. Atmospheric ammonia concentration modulates soil enzyme and microbial activity in 
an oak forest affecting soil microbial biomass. Soil Biology and Biochemistry, v. 116, p.378-387, 2018. Disponivel em:< https://www.sciencedirect.com/science/article/pii/S0038071717306211>.DOI:

10.1016/j.soilbio.2017.10.020.

MANIVASAGAN, P.; VENKATESAN, J.; SIVAKUMAR, K.; KIM, S. K. Pharmaceutically active secondary metabolites of marine actinobacteria. Microbiological Research, v. 169, n. 4, p. 262-278, 2014. Disponível em:< https://www.sciencedirect.com/science/article/pii/S0944501313001250>.DOI:10.1016 /j.micres.2013.07.014.

MCCARTHY, A. J.; WILLIAMS, S. T. Actinomycetes as agents of biodegradation in the environment-a review. Gene, v. 115, n. 1, p. 189-192, 1992. Disponível em:< https://www.sciencedirect.com/science/article/pii/0378111992905587>.DOI: https://DOI.org/10.1016/0378-1119(92)90558-7.

MEENA, B.; RAJAN, L. A.; VINITHKUMAR, N. V.; KIRUBAGARAN, R. Novel marine actinobacteria from emerald Andaman \& Nicobar Islands: a prospective source for industrial and pharmaceutical byproducts. BMC Microbiology, v. 13, n. 145, 2013.Disponivel em:< https://bmcmicrobiol.biomedcentral.com/articles/10.1186/14712180-13-145>.DOI: 10.1186/1471-2180-13-145.

MINOTTO, E.; MILAGRE, L.P.; OLIVEIRAM M.T.; VAN DER SAND, S.T. Enzyme characterization of endophytic actinobacteria isolated from tomato plants. Journal of Advanced Scientific Research, v. 5, n. 2, 2014.Disponível em:< https://www.researchgate.net/profile/Sueli_Van_Der_Sand/publication/264044877_e nzyme_characterization_of_endophytic_actinobacteria_isolated_from_tomato_plants /links/0a85e53cb088819161000000.pdf>.

OSAKI, F.; NETTO, S. P. Flutuação da população de fungos sob floresta ombrófila mista e em povoamento de Pinus taeda. Floresta. v. 42, n. 4, p. 795-808, 2012. Disponível em:< http://revistas.ufpr.br/floresta/article/view/22542/19837>.DOI: 10.5380/rf.v42i4.22542.

PAST: Paleontological Statistics Software Package for Education and Data Analysis. Palaeontologia Electronica, v. 4, n.1, p. 1-9, 2003.

SAKURE, S.; LIMBORE, A.; ZALAKE, M.; JAIGUDE, S. Isolation and characterization of actinomycetes from rhizosphere soil of different plants for antiphytopathogenic activity and stress tolerance. International Journal of Current Microbiology and Applied Sciences, v. 2, p. 379-387, 2015. Disponível em: https://www.ijcmas.com/special/2/Sunita\%20Sakure,\%20et\%20al.pdf>.

SHIVLATA, L.; TULASI, S. Thermophilic and alkaliphilic Actinobacteria: biology and potential applications. Frontiers in Microbiology, v. 6, p. 1014, 2015. Disponível em:< https://www.frontiersin.org/articles/10.3389/fmicb.2015.01014/full>.DOI: 10.3389/fmicb.2015.01014. 
SILVA, V. M.; MARTINS, C. M.; MARTINS, S. C. S. Atividade celulolítica de actinobactérias de região semiárida do Ceará. Enciclopédia Biosfera, v. 11, p. 2026-2036, $2015 . \quad$ Disponível em:< http://www.conhecer.org.br/enciclop/2015b/biologicas/atividade \%20celulolitica.pdf>.DOI: 10.9790/3008-09564247

ŠNAJDR, J. DOBIÁSOVÁ, P.; URBANOVÁ, M; PETRÁNKOVÁ, M.; CAJTHAML, T.; FROUZ, J.; BALDRIAN, P. Dominant trees affect microbial community composition and activity in post-mining afforested soils. Soil Biology and Biochemistry, v. 56, p. 105-115, 2013. Disponível em:< https://www.sciencedirect.com/science/article/pii/S0038071712001873>.DOI:10.1016 /j.soilbio.2012.05.004.

SREEVIDYA, M.; GOPALAKRISHNAN, S.; KUDAPA, H.; VARSHNEY, R. K. Exploring plant growth-promotion actinomycetes from vermicompost and rhizosphere soil for yield enhancement in chickpea. Brazilian Journal of Microbiology, v. 47, n. 1, p. 85-95, 2016. Disponível em< http://www.scielo.br/scielo.php? pid $=$ S151783822016000100085\&script=sci_arttext $>$.DOI: 10.1016/j.bjm.2015.11.030

STONE, M. M.; DEFOREST, J. L.; PLANTE, A. F. Changes in extracellular enzyme activity and microbial community structure with soil depth at the Luquillo Critical Zone Observatory. Soil Biology \& Biochemistry, v. 75, p. 237-247, 2014.Disponível em:< https://www.sciencedirect.com/science/article/pii/S0038071714001370>.DOI:

10.1016/j.soilbio.2014.04.017.

ŠTURSOVÁ, M.; ZIFČÁKOVÁ, L.; LEIGH, M.B.; BURGESS, R.; BALDRIAN, P. Cellulose utilization in forest litter and soil: identification of bacterial and fungal decomposers. FEMS Microbiology Ecology, v. 80, n. 3, p. 735-746,2012. Disponível em:< https://academic.oup.com/femsec/article/80/3/735/445744>. DOI: 10.1111/j.1574-6941.2012.01343.x.

TYC, O. SONG, C; DICKSCHAT, J.S.; VOS, M.; GARBEVA, P. The ecological role of volatile and soluble secondary metabolites produced by soil bacteria. Trends in Microbiology, v.25, n.4, p. 280-292, 2016. Disponivel em < https://www.sciencedirect.com/science/article/pii/S0966842X16301950>.DOI:10.101 6/j.tim.2016.12.002.

URBANOVÁ, M.; ŠNAJDR, J.; BALDRIAN, P. Composition of fungal and bacterial communities in forest litter and soil is largely determined by dominant trees. Soil Biology and Biochemistry, v.84, p.53-64, 2015. Disponível em:< https://www.sciencedirect.com/science/article/pii/S0038071715000565>.DOI: 10.1016/j.soilbio.2015.02.011.

ZANELLA, M. E. Considerações sobre o clima e os recursos hídricos do semiárido nordestino. Caderno Prudentino de Geografia, n. 36, p.126-142, 2014. Disponível em:< http://revista.fct.unesp.br/index.php/cpg/article/view/3176>.Acesso em Março de 2018. 
ŽIFČÁKOVÁ, L.; VĚTROVSKÝ, T.; HOWE, A.; BALDRIAN, P .Microbial activity in forest soil reflects the changes in ecosystem properties between summer and winter. Environmental Microbiology, v. 18, n. 1, p. 288-301, 2016. Disponível em: < http://onlinelibrary.wiley.com/DOI/10.1111/1462-2920.13026/full>.DOI:

10.1111/1462-2920.13026. 